\title{
Traumatic brain injury: The South African landscape
}

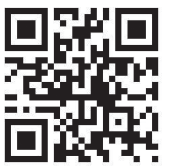

In referring to injuries of the brain the term, 'traumatic brain injury' (TBI) is preferred over the use of the less specific and more generic 'head injury'. While a skull fracture may suggest the presence of an underlying TBI, the presence of neurological symptoms or the demonstration of intracranial pathology is needed to establish the diagnosis of TBI. TBI need not always be caused by direct trauma to the head.

TBI is an extremely important cause of mortality and morbidity in the developed world. In the western hemisphere, TBI is the leading cause of mortality in persons under $45 .{ }^{[1]}$ Population-based studies in countries such as South Africa (SA), Taiwan and India suggest even higher rates in developing countries accounted for primarily by road traffic accidents or motor vehicle accidents (MVAs) ${ }^{[2]}$ Indeed, males in South-East Asia and Africa have the highest and second highest incidences of road traffic injury-related fatalities in the world, ${ }^{[3]}$ and it can be assumed that a significant proportion, if not the majority, of these deaths are attributable to TBI. In the United States (US), where the overall incidence of TBI is 506.4 per 100000 population, ${ }^{[2]}$ equating to approximately 1.5 million people suffering a TBI in each year, a number of states undertake TBI surveillance. This TBI surveillance relies largely on hospital admissions for data collection and ignores mild TBI that does not result in a hospital admission or visit. The overall incidence of TBI is therefore probably higher than officially reported, even in the developed world. SA does not have a TBI databank, and contemporaneous studies on the overall incidence and prevalence of TBI are lacking. In 1991, Brown et al. ${ }^{[4]}$ reported an average incidence of 316 brain injuries per 100000 persons per year. The methodological difficulties in undertaking such a study were well described by the authors. ${ }^{[5]}$ While some of the difficulties alluded to, such as segregated hospitals, no longer apply, others continue to be relevant 22 years later. These include incomplete and unreliable hospital records, poor research (and epidemiological) funding, and overcrowded and poorly resourced public hospitals. A recent developmental accord signed by the national Minister of Health, the Gauteng Health MEC and the ViceChancellor of the University of the Witwatersrand is an encouraging step in the eventual eradication of these persistent shortcomings. ${ }^{[6]}$

A study in 2007 found injury-related mortality rates in SA to be 6 times higher, and the incidence of road traffic injuries to be double, that of the global rate..$^{[7]}$ The major risk factors for TBI are extremes of age, male gender and low socioeconomic status. In the US, the leading cause of TBI are falls, followed by MVAs, being struck by/against objects and assaults. ${ }^{[2]}$ In contrast, in SA, interpersonal violence is a far more frequent cause of mortality and of TBI. In the year 2000, SA's homicide rate was 184 per 100000 people or 9 times the global rate. ${ }^{[7]}$ In 2006 in Cape Town, homicide accounted for $25 \%$ of deaths in males aged 15 years and older. ${ }^{[8]}$ Both studies underscore the intentional nature of trauma in SA.

A further feature, unique to $\mathrm{SA}$, is the large percentage of pedestrians sustaining injury in road traffic accidents. In 2000, pedestrians were involved in $52 \%$ of all road traffic fatalities. ${ }^{[7]}$

TBI is pathophysiologically differentiated into primary and secondary injury. An understanding and appreciation of this among healthcare workers is important in devising strategies to improve TBI outcomes. Such understanding is unfortunately not universal among healthcare workers. A 2007 audit of TBI care in KwaZulu-Natal found the prevention of secondary brain injury to be poorly understood and hence poorly prioritised. ${ }^{[9]}$ Primary injury occurs at the time of impact and is currently believed to be irreversible. Energy transfer to the brain causes irreversible neuronal and mechanical disruption largely in the form of axonal stretching and tearing. ${ }^{[10,11]}$ In addition to direct mechanical injury to the brain parenchyma, primary injury also causes disruption of brain vasculature. Primary injury immediately sets in motion a cascade of secondary inflammatory, oxidative stress, mitochondrial, metabolic and vascular mechanisms that further initiate and perpetuate cellular injury. To date, there has been no successful phase 3 US Food and Drug Administration (FDA) drug trial that targets any of these processes.

Secondary brain injury is maintained and worsened by intracranial and extracranial insults, the combined effects of which are multiplicative rather than additive. Within the skull cavity, raised intracranial pressure from cerebral oedema or an expanding space-occupying lesion are the major contributors to continuing the secondary injury cascade. Systemically, the major causes of secondary brain injury and poor patient outcomes in TBI are hypotension and hypoxia. Metabolic (hypo- and hyperglycaemia) and electrolyte abnormalities are also implicated in worsening secondary injury. Hyperglycaemia contributes to secondary brain injury by worsening intracellular acidosis as it provides a substrate for continued anaerobic metabolism. Whether prevention of hyperglycaemia, particularly in severe TBI, improves outcome is yet to be conclusively established. ${ }^{[12]}$

Numerous studies have demonstrated an association between hypotension (systolic blood pressure $<90 \mathrm{mmHg}$ ) and poor outcome in TBI. ${ }^{[10]}$ The relationship between poor TBI outcome and hypotension appears to be independent of age, number of associated injuries, mechanism of injury or even transport time to treatment. ${ }^{[13]}$ The injured brain is particularly vulnerable to hypotension because cerebral autoregulation is frequently disturbed ${ }^{[14]}$ Autoregulation has been shown to be impaired even in patients who sustain mild TBIs, ${ }^{[15]}$ the degree of impairment generally being proportional to the severity of TBI. The loss of autoregulation means that the injured brain is more prone to ischaemia because cerebral perfusion pressure is proportional to, and entirely dependent on, mean arterial pressure. ${ }^{[16]}$ Because of the brain's ability to extract oxygen, provided cerebral perfusion pressure is maintained, hypotension may be a stronger predictor of eventual poor outcome than hypoxia. ${ }^{[10,17]}$ The 'scoop and run' approach advised in much of the general surgical literature may therefore be inappropriate in patients who have suffered TBI. On-scene haemodynamic resuscitation however, must not be unduly delayed, particularly in those patients suspected of harbouring expanding intracranial mass lesions.

It has been demonstrated that decreased brain tissue oxygenation $\left(\mathrm{PbO}_{2}\right)$ is predictive of poor outcome following TBI, and brain oxygenation is strongly linked to systemic oxygenation. ${ }^{[18]}$ Patients with TBI are at risk of airway obstruction, aspiration and consequent hypoxia. Therefore endotracheal intubation at the scene of injury would intuitively seem to be an effective method of preventing hypoxia and consequent brain energy failure. However, endotracheal intubation is itself associated with risks of aspiration, hypoxia and increased intracranial pressure even under the controlled circumstances of an operating theatre. Further endotracheal intubation and subsequent positive pressure ventilation exposes the patient to the risks of hyperventilation and increased intrathoracic pressure. Hyperventilation causes hypocarbia, which induces cerebral vasoconstriction. Increased intrathoracic pressure decreases venous return, which may impair cerebral perfusion pressure, particularly in hypovolemic patients. Rapid sequence intubation (RSI) is thought to be the technique of choice for the pre-hospital intubation of TBI patients as it does not increase intracranial pressure and reduces the risk of aspiration. In the current issue of the SAMJ, Gunning et al. ${ }^{[19]}$ found that RSI intubation is effectively performed in the pre-hospital setting but with a high incidence of adverse effects. In a thought-provoking study, Sobuwa et al.,[20] somewhat counterintuitively, found that patients intubated using the RSI technique had the poorest outcomes when compared with a cohort of patients who had other forms of pre-hospital airway management. 
TBI is an economically, socially and personally devastating condition, which clearly epitomises the adage that 'prevention is better than cure'. For the foreseeable future, improved patient outcomes will depend on organised trauma response systems, particularly to prevent the potentially reversible effects of secondary brain injury. In the US, the Brain Trauma Foundation (http://www.braintrauma.org) has shown that such systems provide improved patient outcomes and, if widely adopted, have the potential to provide massive savings in associated costs. SA needs improved and current TBI epidemiological data to develop protocols appropriate to our unique set of conditions, such as the high incidence of intentional TBI, high proportion of pedestrian vehicle accidents and limited and unequal availability of resources. The Kimberley Hospital Rule study ${ }^{[2]}$ and the epidemiological survey from Red Cross War Memorial Hospital, ${ }^{[22]}$ also in this issue, are excellent examples of the data needed to compile relevant TBI prevention and treatment strategies.

\section{Dinesh Naidoo}

Charlotte Maxeke Johannesburg Academic Hospital, University of the Witwatersrand, Johannesburg, South Africa

\section{Corresponding author: D Naidoo (dineshnaidoo@yahoo.com)}

1. Okonkwo DO. Introduction: Traumatic brain injury. Neurosurg Focus 2008;25(4):E1.

2. Corrigan JD, Selassie AW, Orman JA. The epidemiology of traumatic brain injury. J Head Trauma Rehabil 2010;25(2):72-80. [http://dx.doi.org/10.1097/HTR.0b013e3181ccc8b4]

3. Bowman B, Seedat M, Duncan N, Kobusingye O. Disease and Mortality in sub-Saharan Africa. 2nd edition. Jamison DT, Feachem RG, Makgoba MW, et al., eds. Washington: World Bank, 2006.

4. Brown DSO, Nell V. Epidemiology of traumatic brain injury in Johannesburg - II. Morbidity, Mortality and Etiology. Soc Sci Med 1991;33(3):289-296. [http://dx.doi.org/10.1016/0277-9536(91)90363-H]
5. Brown DSO, Nell V. Epidemiology of traumatic brain injury in Johannesburg - I. Methodological issues in a developing country context Soc SciMed 1991:33(3).283-287. [http.//dx doiorg/101016/0277-9536(91)90362-G] 6. Wits Media Centre. Wits vows to address healthcare challenges. http://www.wits.ac.za/newsroom/ 6. Wits Media Centre. Wits vows to address healthcare challenges. http://www
newsitems/201307/20759/news_item_20759.html (accessed 31 July 2013).

7. Norman R, Matzopoulos R, Groenewald P, Bradshaw D. The high burden of injuries in South Africa. Bull World Health Organ 2007;85(9):695-702. [http://dx.doi.org/10.2471/BLT.06.037184]

8. Groenewald P, Bradshaw D, Daniels I, et al. Cause of death and premature mortality in Cape Town, 8. Groenewald P, Bradshaw D, Daniels I, et al. Cause of death and premature mortality in Cape Town,
2001 - 2006. Cape Town: South African Medical Research Council, 2008. http://www.mrc.ac.za/bod/ 2001 - 2006. Cape Town: South African M

9. Alexander T, Fuller G, Hargovan P. An audit of the quality of care of traumatic brain injury at a busy . Alexander T, Fuller G, Hargovan P. An audit of the quality of care
regional hospital in South Africa. S Afr J Surg 2009;47(4):120-126.

regional hospital in South Africa. S Afr J Surg 2009;47(4):120-126.
10. Stiver SI, Manley GT. Prehospital management of traumatic brain injury. Neurosurg Focus 2008;25(4):1-11.

10. Stiver SI, Manley GT. Prehospital management of traumatic brain injury. Neurosurg Focus 2008;25(4):1-11.
11. Langfitt TW, Gennaralli TA. Can the outcome from head injury be improved? J Neurosurg Langfitt TW, Gennaralli TA. Can the outcome from head
1982;56(1):19-25. [http://dx.doi.org/10.3171/jns.1982.56.1.0019]

12. Rovlias A, Kotsou S. The influence of hyperglycemia on neurological outcome in patients with severe head injury. Neurosurgery 2000;46(2):335-342. [http://dx.doi.org/10.1097/00006123-200002000-00015] 13. Kokoska ER, Smith GS, Pittman T, Weber TR. Early hypotension worsens neurological outcome in pediatric patients with moderately severe head trauma. J Pediatr Surg 1998;33(2):333-338.

14. Czosnyka M, Smielewski P, Piechnik S, Steiner LA, Pickard JD. Cerebral autoregulation following head injury. J Neurosurg 2001;95(5):756-763. [http://dx.doi.org/10.3171/jns.2001.95.5.0756]

15. Jünger EC, Newell DW, Grant GA, et al. Cerebral autoregulation following minor head injury. J Neurosug 1997;86(3):425-432. [http://dx.doi.org/10.3171/jns.1997.86.3.0425]

16. Bullock MR, du Trevou MD, van Dellen JR, Nel JP, McKeown CP. Prevention of death from head injury in Natal. S Afr Med J 1988;73(9):523-527.

17. Chesnut RM, Marshall LF, Klauber MR, et al. The role of secondary brain injury in determining outcome from severe head injury. J Trauma 1993;34(2):216-222. [http://dx.doi.org/10.1097/00005373-199302000-00006]

18. Rosenthal G, J. Hemphill C, Sorani M, et al. The role of lung function in brain tissue oxygenation following traumatic brain injury. J Neurosurg 2008;108(1):59-65. [http://dx.doi.org/10.3171//NS/2008/108/01/0059]

19. Gunning M, Perkins Z, Crilly J, von Rahden R. Paramedic rapid sequence induction (RSI) in a South African emergency medical service: A retrospective observational study. S Afr Med J 2013;103(9):632-637. [http://dx.doi.org/10.7196/SAMJ.6656]

20. Sobuwa S, Hartzenberg HB, Geduld H, Uys C. Outcomes following prehospital airway management in severe traumatic brain injury. S Afr Med J 2013;103(9):644-646. [http://dx.doi.org/10.7196/SAMJ.7035]

21. Bezuidenhout AF, Hurter D, Maydell AT, et al. The Kimberley Hospital Rule (KHR) for urgent computed tomography of the brain in a resource-limited environment. S Afr Med J 2013;103(9):646-651. [http://
to dx.doi.org/10.7196/SAMJ.6876]

22. Schrieff LE, Thomas KGF, Dollman AK, Rohlwink UK, Figaji AA. Demographic profile of severe 2. Schrieff LE, Thomas KGF, Dollman AK, Rohlwink UK, Figaji AA. Demographic profile of severe
traumatic brain injury admissions to Red Cross War Memorial Children's Hospital, 2006 - 2011. S Afr traumatic brain injury admissions to Red Cross War Memorial Chil
Med J 2013;103(9):616-620. [http://dx.doi.org/10.7196/SAMJ.7137]

S Afr Med J 2013;103(9):613-614. DOI:10.7196/SAMJ.7325 